\title{
PENGARUH ORIENTASI PASAR, INOVASI PRODUK DAN INKLUSI KEUANGAN TERHADAP KINERJA UKM
}

\section{Retno Setyowati}

Fakultas Ekonomi, Universitas Slamet Riyadi Surakarta rsetyowati18@gmail.com

\section{Marjam Desma Rahadhini}

Fakultas Ekonomi, Universitas Slamet Riyadi Surakarta rahadhininew@gmail.com

\section{Aris Eddy Sarwono}

Fakultas Ekonomi, Universitas Slamet Riyadi Surakarta arissarwono74@gmail.com

\begin{abstract}
The purpose of this study is to analyze the effect of market orientation, product innovation and financial inclusion on the performance of SMES. This research is a survey research. The population of this research is striated weaving UKM in Mlese Village, Cawas, Klaten. Collecting data using a questionnaire. The sampling technique used the accidental sampling method, namely the striated weaving UKM in Mlese Village, Cawas, Klaten. The sample is 114 respondents. The validity test uses the Pearson correlation product moment, and Cronbach's Alpha for reliability testing. Data analysis used multiple linear regression. The results show that market orientation has a significant effect on the performance of SMES, product innovation has a significant effect on the performance of SMES, and financial inclusion has a significant effect on the performance of SMEs.
\end{abstract}

Keywords: market orientation; product innovation; financial inclusion; SME performance.

$\triangle$ Corresponding author:

Email Address : rsetyowati18@gmail.com (Surakarta, Jawa Tengah)

Received 30 November 2021, Accepted 6 Pebruari 2022, Published 23 Pebruari 2021

\section{PENDAHULUAN}

Usaha kecil menengah adalah suatu aspek penting dalam pembangunan ekonomi. Banyak UKM yang bermunculan hingga usaha besar yang terus berkembang, menjadikan persaingan tidak dapat dihindari. Tekanan usaha dari pesaing yang kuat bisa mempengaruhi kinerja pada UKM. Kinerja UKM merupakan sebuah tolak ukur capaian perusahaan dalam memasarkan produknya.

Kinerja UKM merupakan sebuah rancangan yang digunakan untuk memperkirakan prestasi suatu perusahaan pada pasar terhadap suatu produk (Nasution, n.d.). UKM tenun adalah salah satu sub sektor industri kreatif yang ada di Indonesia, sub sektor ini dapat diartikan sebagai produksi tekstil khas Indonesia yang dimiliki oleh pelaku usaha tenun yang cara produksinya masih tradisional. usaha tenun yang cara produksinya masih tradisional.

Salah satu UKM tenun yang masih berkembang hingga saat ini, yaitu: UKM Tenun Lurik di Desa Mlese, Cawas, Klaten. Terdapat 160 UKM Tenun Lurik di Desa Mlese, Cawas, Klaten yang bergabung dalam sebuah paguyuban yang berada dibawah pengawasan kepala desa, camat \& dinas koperasi, usaha kecil dan menengah Kabupaten Klaten. Banyaknya UKM tenun lurik membuat persaingan usaha yang sulit dihindari Kemampuan usaha tenun untuk mempelajari keinginan, kebutuhan serta mempersiapkan produk keinginan dan kebutuhan konsumen merupakan orientasi pasar.

Orientasi pasar yang ditunjukkan menggunakan cara UKM selalu berusaha mengidentifikasi kebutuhan dan impian 
konsumen, memuaskan konsumen, mencari tentang pesaing, dan melakukan koordinasi antar fungsi pada usahanya. Orientasi pasar merupakan suatu cara dan kegiatan yang berkaitan dengan penciptaan dan pemenuhan kepuasan pelanggan dengan cara mengidentifikasi kebutuhan atau keinginan pelanggan (firmansyah, 2019). Penelitian dari (Udriyah et al., 2019) yang menyatakan bahwa orientasi pasar berpengaruh terhadap kinerja UKM, sedangkan penelitian dari (Niaga et al., 2018) menjelaskan bahwa orientasi pasar tidak berpengaruh terhadap kinerja UKM.

Orientasi pasar sangat diperlukan sebelum suatu usaha melakukan inovasi produk, agar inovasi produk dapat sesuai dengan keinginan dan kebutuhan konsumen. Inovasi merupakan suatu proses untuk mengubah kesempatan menjadi ide yang dapat dipasarkan, serta gagasan murni yang memegang peranan penting dan pikiran kreatif yang dikembangkan menjadi gagasan berharga (Reniati, 2013). Inovasi produk merupakan hal yang perlu mendapat perhatian utama dari suatu usaha. Inovasi produk dengan biaya yang rendah dapat meningkatkan keuntungan dengan menarik konsumen yang baru dari pasar yang belum dimanfaatkan oleh pesaing.

Penelitian (Miftakhul, Anugrahini, Hadi, n.d.) menyatakan bahwa inovasi produk berpengaruh terhadap kinerja UKM sedangkan penelitian dari (Susilowati et al., n.d.) menjelaskan bahwa inovasi produk tidak berpengaruh terhadap kinerja UKM. UKM membutuhkan akses keuangan untuk memperoleh modal. Kemudahan untuk memperoleh dana/pinjaman merupakan hal penting bagi masyarakat dalam menjalankan UKM (Nengsih \& Nonia, 2015).

Inklusi keuangan adalah kemampuan seseorang dalam mendapatkan akses berbagai barang \& jasa keuangan yang terjangkau \& sesuai kebutuhan (Riwayati, 2017). Inklusi keuangan berperan dalam meningkatkan kesejahteraan masyarakat, mendorong proses proses pemulihan ekonomi nasional, dan mendukung daya tahan ekonomi masyarakat. Penelitian dari (Sanistasya et al., 2018) yang menyatakan bahwa inklusi keuangan berpengaruh terhadap kinerja UKM sedangkan penelitian dari (Ruli et al., 2021) menjelaskan bahwa inovasi produk tidak berpengaruh terhadap kinerja UKM.

\section{METODOLOGI PENELITIAN}

Variabel independen penelitian ini adalah orientasi pasar, inovasi produk \& inklusi keuangan. Variabel dependen dalam penelitian ini yaitu kinerja UKM, dengan model penelitian sebagai berikut:

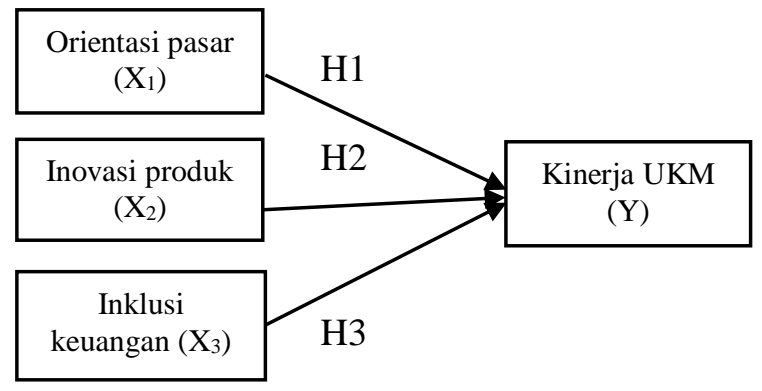

Gambar 1. Kerangka Berfikir Penelitian

\section{Populasi \& Sampel}

Populasi dalam penelitian ini adalah UKM tenun lurik yang berada di Desa Mlese, Cawas, Klaten. Pengambilan sampel menggunakan teknik probability sampling yaitu sampel secara kebetulan (accidental sampling). Populasi dari penelitian yaitu 160 pelaku UKM tenun lurik sehingga sampel ditentukan dengan menggunakan rumus Slovin. Sampel yang digunakan sebanyak 114 pelaku UKM tenun lurik di Desa Mlese, Cawas, Klaten.

\section{Pengumpulan dan Analisis Data}

Data yang digunakan pada penelitian ini merupakan data primer yang diperoleh langsung dari responden, melalui penyebaran kuesioner. Penelitian ini menggunakan analisis regresi linier berganda yang menggunakan program SPSS versi 25. Sebelum dilakukan uji analisis regresi linier berganda terhadap hipotesis penelitian, maka akan dilakukan pengujian asumsi klasik. Data yang diolah dengan uji multikolinearitas dengan melihat nilai VIF dari setiap variabel independen.

Jika nilai VIF <10. Uji autokorelasi menggunakan uji run test dengan nilai signifikansi $>0,05$. Uji heteroskedastisitas yang di uji menggunakan uji Glejser dengan signifikansi $>0,05$. Uji normalitas apabila mempunyai nilai signifikansi $>0,05$. Selanjutnya dilakukan pengujian hipotesis untuk mencari tahu pengaruh variabel independent $(\mathrm{X})$ terhadap variabel dependent (Y). Analisis regresi linier berganda dilakukan 
dengan uji t, uji $F$ serta uji koefisien determinasi.

Definisi operasional variabel yang digunakan sebagai berikut:

1. Orientasi pasar

Orientasi pasar adalah suatu kegiatan yang dilakukan untuk mencari informasi pasar, mulai kebutuhan pelanggan yang sekarang maupun yang akan datang sehingga UKM tenun lurik dapat mengetahui kondisi pasar. Terdapat tiga indikator untuk mengukur orientasi pasar yaitu orientasi pesaing, orientasi pelanggan dan koordinasi antar fungsi (Tjiptono, 2012)

2. Inovasi produk

Inovasi produk merupakan kemampuan dalam menciptakan suatu ide/gagasan baru yang dilakukan oleh UKM tenun lurik dalam memuaskan konsumen. Terdapat tiga indikator inovasi produk dalam penelitian ini yaitu kultur inovasi produk, inovasi teknik dan inovasi produk (Reniati, 2013)

3. Inklusi keuangan

Inklusi keuangan misalnya akses terhadap produk keuangan yang sesuai mulai dari kredit, tabungan, asuransi, \& pembayaran, tersedianya akses yang mengesankan terhitung kenyamanan, keterjangkauan, kesesuaian, \& gunakan mengamati tunjangan konsumen, beiring ketersediaan yang diberikan kepada pemilik UKM tenun lurik pada Desa Mlese. Indikator pada analisis ini mengakui analisis (Yanti, 2019) yang menyatakan ada empat indikator inklusi keuangan, yaitu ketersediaan akses, penggunaan, nilai \& kesejahteraan.

4. Kinerja UKM

Kinerja merupakan hasil suatu pekerjaan yang berkaitan terhadap tujuan strategis UKM, kepuasan konsumen, dan memberi kontribusi terhadap ekonomi UKM tenun lurik. Indikator dalam penelitian ini mengadopsi penelitian dari (Rapih et al., 2015) Indikator penelitian ini yaitu pertumbuhan pelanggan, pertumbuhan keuntungan, serta pertumbuhan penjualan.

\section{HASIL PENELITIAN}

Berdasarkan hasil kuesioner yang didistribusikan kepada 114 responden, dapat diketahui hasil pengujian validitas seluruh item variabel menunjukkan valid, karena diperoleh nilai koefisien kurang dari 0,05. Menurut hasil uji reliabilitas seluruh item variabel mempunyai nilai Cronbach's Alpha $>0,60$ yang menunjukkan reliabel. Deskripsi umum responden menurut jenis kelamin, usia serta lama menjalankan usaha disimpulkan bahwa responden perempuan sebesar (78\%), usia responden antara 57-67 tahun sebesar $(58,8 \%)$ dan lama menjalankan usaha antara 11-20 tahun sebesar $(80,7 \%)$.

\section{Uji Asumsi Klasik}

Hasil dari uji asumsi klasik yaitu:

Tabel 1. Hasil Uji Asumsi Klasik

\begin{tabular}{|l|l|c|}
\hline \multicolumn{1}{|c|}{ Uji Asumsi Klasik } & \multicolumn{1}{|c|}{ Hasil Uji } & Ket. \\
\hline Uji Multikolinearitas & $\begin{array}{l}\text { Tolerance }(0,481) ; \\
(0,576) ;(0,388)>0,10\end{array}$ & Lolos uji \\
& $\begin{array}{l}\text { VIF }(2,080) ;(1,735) ; \\
(2,577)<10\end{array}$ & \\
\hline Uji Autokorelasi & $\mathrm{p}(0,132)>0,05$ & Lolos uji \\
\hline Uji Heteroskedastisitas & $\begin{array}{l}\mathrm{p}(0,252) ;(0,666) ; \\
(0,665)>0,05\end{array}$ & Lolos uji \\
\hline Uji Normalitas & $\mathrm{p}(0,878)>0,05$ & Lolos uji \\
\hline
\end{tabular}

Sumber: Data primer diolah, 2021

Berdasarkan Tabel 1. menunjukkan bahwa uji asumsi klasik (uji multikolinearitas, uji autokorelasi, uji heteroskedasitas, dan uji normalitas) semua telah lolos uji, sehingga uji hipotesis dapat dilakukan.

Tabel 2. Uji Regresi Linier Berganda

\begin{tabular}{|c|c|c|c|c|c|c|}
\hline \multicolumn{7}{|c|}{ Coefficients $^{\mathrm{a}}$} \\
\hline & \multirow{2}{*}{ Model } & \multicolumn{2}{|c|}{$\begin{array}{l}\text { Unstandardized } \\
\text { Coefficients }\end{array}$} & \multirow{2}{*}{$\begin{array}{c}\begin{array}{l}\text { Standardized } \\
\text { Coefficients }\end{array} \\
\text { Beta } \\
\end{array}$} & \multirow[t]{2}{*}{$\mathrm{t}$} & \multirow{2}{*}{ Sig. } \\
\hline & & B & Std. Error & & & \\
\hline \multirow{4}{*}{1} & (Constant) & 3,819 & 10,219 & & 3,134 & 0,002 \\
\hline & $\begin{array}{l}\text { Orientasi } \\
\text { pasar }\end{array}$ & 0,250 & 0,073 & 0,279 & 3,402 & 0,001 \\
\hline & $\begin{array}{l}\text { Inovasi } \\
\text { produk }\end{array}$ & 0,287 & 0,065 & 0,329 & 4,399 & 0,000 \\
\hline & $\begin{array}{l}\text { Inklusi } \\
\text { keuangan }\end{array}$ & 0,301 & 0,086 & 0,318 & 3,487 & 0,001 \\
\hline
\end{tabular}

Sumber: Data primer diolah, 2021

Berdasarkan Tabel 2. didapatkan persamaan regresi serta hasil koefisien resgresinya, yaitu:

$\mathrm{Y}=3,819+0,250 \mathrm{X} 1+0,287 \mathrm{X} 2+0,301 \mathrm{X} 3$

Dijelaskan bahwa $\mathrm{Y}=$ kinerja UKM; $\mathrm{X} 1=$ orientasi pasar; $\mathrm{X} 2=$ inovasi produk; $\mathrm{X} 3=$ Inklusi keuangan. Angka koefisien regresi X1 (orientasi pasar) sebesar 0,250 artinya apabila X1 meningkat maka kinerja UKM juga akan meningkat, dengan anggapan variabel inovasi produk dan inklusi keuangan tetap.

Koefisien bernilai positif, sehingga orientasi pasar berpengaruh positif terhadap variabel kinerja UKM. Angka koefisien regresi X2 (inovasi produk) yaitu 0,287 berarti apabila 
X2 meningkat maka kinerja UKM juga akan meningkat, dengan asumsi variabel lain (orientasi pasar dan inklusi keuangan) tetap. Koefisien bernilai positif, yang berarti inovasi produk berpengaruh positif terhadap variabel kinerja UKM.

Angka koefisien regresi X3 (inklusi keuangan) yaitu 0,0301 berarti apabila X3 meningkat maka kinerja UKM juga akan meningkat, dengan anggapan variabel lain (orientasi pasar dan inovasi produk) tetap. Koefisien bernilai positif, maka inklusi keuangan memiliki pengaruh positif bagi variabel kinerja UKM.

\section{Uji Hipotesis}

\section{Uji t}

Tabel 3. Hasil Uji t

\begin{tabular}{|l|r|l|l|l|}
\hline \multicolumn{1}{|c|}{ Variabel } & $\begin{array}{c}\text { Nilai } \\
\text { Kritis }\end{array}$ & T & Sig & Kesimpulan \\
\hline Orientasi pasar & 0,05 & 3,402 & 0,001 & signifikan \\
\hline Inovasi produk & 0,05 & 4,399 & 0,000 & signifikan \\
\hline Inklusi keuangan & 0,05 & 3,487 & 0,001 & Signifikan \\
\hline
\end{tabular}

Sumber: Data primer diolah, 2021

Berdasarkan Tabel 3. didapatkan hasil uji t variabel orientasi pasar (X1) menunjukkan nilai t hitung 3,402 serta $\rho$-value sebesar 0,001 $<0,05$ berarti H1 diterima, dimana orientasi pasar mempunyai pengaruh signifikan terhadap kinerja UKM. Variabel inovasi produk diperoleh nilai $\mathrm{t}$ hitung 4,399 serta $\rho$-value sebesar $0,000<0,05$ berarti $\mathrm{H} 2$ diterima, dimana inovasi produk berpengaruh signifikan terhadap kinerja UKM. Variabel inklusi keuangan diperoleh nilai t hitung 3,487 serta $\rho$ value sebesar $0,001<0,05$ berarti H3 diterima, dimana inklusi keuangan berpengaruh signifikan terhadap kinerja UKM.

\section{Uji F}

\begin{tabular}{|l}
\multicolumn{8}{|c|}{ Tabel 4. Uji F } \\
\begin{tabular}{|c|l|c|c|c|c|c|}
\hline \multicolumn{2}{|c|}{ ANOVA $^{\mathbf{a}}$} \\
\hline \multirow{2}{*}{ Model } & $\begin{array}{c}\text { Sum of } \\
\text { Squares }\end{array}$ & Df & $\begin{array}{c}\text { Mean } \\
\text { Square }\end{array}$ & F & Sig. \\
\hline \multirow{3}{*}{1} & Regression & 350,545 & 3 & 116,848 & 66,634 & $0,000^{\mathrm{b}}$ \\
\cline { 2 - 8 } & Residual & 192,893 & 110 & 1,754 & & \\
\cline { 2 - 8 } & Total & 543,439 & 113 & & & \\
\hline
\end{tabular}
\end{tabular}

Sumber: Data primer diolah, 2021

Berdasarkan perhitungan tabel 7 diperoleh model regresi ini memiliki nilai $\mathrm{F}$ hitung 66,634 dengan nilai p-value yaitu 0,000 $<0,05$. Sehingga H0 ditolak \& Ha diterima, berarti model regresi ini sesuai dalam menaksir pengaruh orientasi pasar (X1), inovasi produk (X2), dan inklusi keuangan (X3) terhadap variabel kinerja UKM (Y).

\section{Uji Koefisien Determinasi (R2)}

Tabel 5. Uji Koefisien Determinasi (R2)

\begin{tabular}{|c|c|c|c|c|c|c|c|c|c|}
\hline \multicolumn{10}{|c|}{ Model Summary } \\
\hline \multirow[b]{2}{*}{ Model } & \multirow[b]{2}{*}{$\mathrm{R}$} & \multirow[b]{2}{*}{$\begin{array}{l}\mathrm{R} \\
\text { Square }\end{array}$} & \multirow[b]{2}{*}{$\begin{array}{l}\text { Adjusted } \\
\text { R Square }\end{array}$} & \multirow[b]{2}{*}{$\begin{array}{l}\text { Std. Error } \\
\text { of the } \\
\text { Estimate }\end{array}$} & \multicolumn{5}{|c|}{ Change Statistics } \\
\hline & & & & & $\begin{array}{l}\mathrm{R} \\
\text { Square } \\
\text { Chang } \\
\mathrm{e}\end{array}$ & $\begin{array}{l}\text { F } \\
\text { Chan } \\
\text { ge }\end{array}$ & $\begin{array}{l}\mathrm{df} \\
1\end{array}$ & $\begin{array}{l}\text { df } \\
2\end{array}$ & $\begin{array}{l}\text { Sig. } \\
\text { F } \\
\text { Chan } \\
\text { ge }\end{array}$ \\
\hline 1 & $0,803^{\mathrm{a}}$ & 0,645 & 0,635 & 1,32423 & 0,645 & $\begin{array}{l}66,63 \\
4\end{array}$ & 3 & $\begin{array}{l}11 \\
0\end{array}$ & $\begin{array}{l}0,00 \\
0\end{array}$ \\
\hline
\end{tabular}

Sumber: Data primer diolah, 2021

Hasil pengujian koefisien determinasi pada Tabel 5. yaitu: sebesar 0,635 yang berarti besarnya sumbangan pengaruh variabel orientasi pasar (X1), inovasi produk (X2), \& inklusi keuangan (X3) terhadap variabel kinerja UKM (Y) pada UKM tenun lurik di Desa Mlese, Cawas, Klaten sebesar $63,5 \%$ dengan sisa $36,5 \%$ yang mendapat pengaruh dari variabel lain yang tidak diteliti.

\section{PEMBAHASAN}

(Firmansyah, 2019) mendefinisikan orientasi pasar sebagai suatu proses dan aktivitas yang berkaitan dengan penciptaan dan pemenuhan kepuasan pelanggan dengan cara mengidentifikasi kebutuhan atau keinginan pelanggan. Berdasarkan hasil penelitian yang diperoleh menyatakan orientasi pasar mempunyai pengaruh signifikan terhadap kinerja UKM, yang dibuktikan dengan nilai $\mathrm{p}$ value $(0,001)<0,05$ sehingga $\mathrm{H} 0$ ditolak \& Ha diterima. Hipotesis pertama menyatakan "orientasi pasar (X1) berpengaruh signifikan terhadap kinerja UKM (Y)" terbukti kebenaranya.

Implikasi penelitian ini sebaiknya UKM tenun lurik semakin meningkatkan orientasi pasar yaitu dalam pembuatan tenun lurik sebaiknya sesuai dengan keinginan dan selalu menjaga untuk mampu memenuhi keinginan pelanggan yang membeli kain tenun lurik. Penelitian yang sejalan yaitu penelitian (Udriyah et al., 2019) yang menyatakan orientasi pasar berpengaruh signifikan terhadap kinerja UKM. Persamaan dari penelitian tersebut dengan penelitian sekarang terdapat pada variabel yang diteliti sedangkan perbedaannya terletak pada objek penelitian dan alat analisis yang digunakan. 
Inovasi menurut (Reniati, 2013) merupakan suatu proses untuk mengubah kesempatan menjadi ide yang dapat dipasarkan, serta gagasan murni yang memegang peranan penting dan pikiran kreatif yang dikembangkan menjadi gagasan berharga. Berdasarkan hasil penelitian yang diperoleh menyatakan inovasi produk mempunyai pengaruh signifikan terhadap kinerja UKM, yang dibuktikan dengan nilai p- value $(0,000)<0,05$ sehingga $\mathrm{H} 0$ ditolak dan Ha diterima, maka hipotesis kedua menyatakan "inovasi produk (X2) berpengaruh signifikan terhadap kinerja UKM (Y)" terbukti kebenarannya.

Implikasi dari penelitian ini sebaiknya UKM tenun lurik lebih memperhatikan dan meningkatkan inovasi teknik yaitu dengan meningkatkan proses produksi yang lebih efektif serta efisien dan dapat menciptakan/ menghasilkan tenun lurik dengan berbagai macam motif. Penelitian yang sejalan yaitu penelitian Miftakhul, Anugrahini, Hadi (2019), yang menyatakan inovasi produk berpengaruh signifikan terhadap kinerja UKM. Persamaan dari penelitian tersebut dengan penelitian sekarang terdapat pada variabel yang diteliti dan alat analisis yang digunakan sedangkan perbedaannya terletak pada objek penelitian.

Inklusi keuangan adalah seluruh upaya dalam meniadakan segala bentuk hambatan terhadap akses masyarakat dalam pemanfaatan layanan jasa keuangan dengan biaya terjangkau (Soetiono, 2018). Berdasarkan hasil penelitian yang diperoleh menyatakan inklusi keuangan mempunyai pengaruh signifikan terhadap kinerja UKM, yang dibuktikan dengan nilai pvalue sebesar $(0,001)<0,05$, sehingga $\mathrm{H} 0$ ditolak \& Ha diterima, maka hipotesis ketiga yaitu "inklusi keuangan (X3) berpengaruh signifikan terhadap kinerja UKM (Y)" terbukti kebenarannya.

Implikasi penelitian ini, yaitu: pemerintah sebaiknya lebih meningkatkan ketersediaan layanan jasa keuangan dapat digunakan UKM untuk menambah modal kerja dan meningkatkan kesejahteraaan, serta menjamin ketersediaan akses keuangan dengan cara lembaga keuangan menyediakan layanan jasa keuangan yang dapat digunakan UKM. Penelitian yang sama yaitu penelitian (Sanistasya et al., 2018) yang menyatakan inklusi keuangan berpengaruh signifikan terhadap kinerja UKM. Persamaan dari penelitian tersebut dengan penelitian sekarang terdapat pada variabel yang diteliti sedangkan perbedaannya terletak pada objek penelitian dan alat analisis yang digunakan.

\section{KESIMPULAN}

Kesimpulan dari penelitian ini yaitu orientasi pasar, inovasi produk, inklusi keuangan berpengaruh signifikan terhadap kinerja UKM tenun lurik di Desa Mlese, Cawas, Klaten.

Saran yang diberikan peneliti dalam penelitian ini yaitu:

1. UKM tenun lurik di Desa Mlese, Cawas, Klaten hendaknya lebih memahami pembuatan kain tenun lurik yang sesuai dengan keinginan dan selera pelanggan.

2. UKM tenun lurik di Desa Mlese, Cawas, Klaten hendaknya meningkatkan proses produksi menjadi lebih efektif \& efisien.

3. UKM tenun lurik di Desa Mlese, Cawas, Klaten hendaknya memanfaatkan layanan jasa keuangan untuk menambah modal kerja dan meningkatkan kesejahteraan usahanya.

4. Peneliti berikutnya sebaiknya melakukan penelitian dengan menggunakan variabel diluar penelitian ini, seperti orientasi kewirausahaan, modal sosial dan literasi keuangan.

Penelitian ini terdapat keterbatasan antara lain:

1. Pengambilan data pada UKM tenun lurik di Desa Mlese, Cawas, Klaten harus dilakukan pendampingan dan dipandu saat mengisi kuesioner karena ada pertanyaan yang harus dijelaskan kepada responden agar lebih paham.

2. Penelitian ini hanya dilakukan pada UKM tenun lurik di Desa Mlese, Cawas, Klaten maka hasil penelitian ini tidak bisa digeneralisasikan di tempat lain.

\section{DAFTAR PUSTAKA}

Firmansyah. (2019). Pemasaran (Dasar dan Konsep). Qiara Media. Pasuruan

Miftakhul, Anugrahini, Hadi. 2019. "Pengaruh orientasi kewirausahaan dan inovasi produk terhadap kinerja UMKM batik gedog khas Tuban". EcoEntrepreneurship, Vol. 5, No. 1, Hal. $33-48$

Nasution, A. Arief. 2014. (n.d.). Analisis Kinerja Pemasaran PT Alfa Scorpii Medan. 
Nengsih, \& Nonia. (2015). Peran Perbankan Syariah dalam Mengimplikasikan Keuangan Inklusif di Indonesia. Jurnal Ekonomi, 14, 221-240.

Niaga, A., Tinggi, S., Administrasi, I., \& Jember, P. (2018). KINERJA UMKM NUNGKY VIANA FERANITA HENDRA ARIS SETIAWAN. In Majalah Ilmiah "DIAN ILMU (Vol. 18, Issue 1).

Rapih, S., Martono, T., \& Riyanto, G. (2015). Analisis Pengaruh Kompetensi Sumber Daya Manusia, Modal Sosial dan Modal Finansial terhadap Kinerja UMKM Bidang Garmen di Kabupaten Klaten. Jurnal Pendidikan Insan Mandiri, 1, 120.

Reniati. (2013). Kreativitas Organisasi dan Inovasi Bisnis. Alfabeta. Bandung

Riwayati, H. E. (2017). International Journal of Economics and Financial Issues Financial Inclusion of Business Players in Mediating the Success of Small and Medium Enterprises in Indonesia. International Journal of Economics and Financial Issues, 7(4), 623-627. http:www.econjournals.com

Ruli, M., Hilmawati, N., \& Kusumaningtias, R. (2021). Nominal: Barometer Riset Akuntansi dan Manajemen INKLUSI KEUANGAN DAN LITERASI KEUANGAN TERHADAP KINERJA DAN KEBERLANGSUNGAN SEKTOR USAHA MIKRO KECIL MENENGAH. 10(1).

Sanistasya, P. A., Rahardjo, K., \& Iqbal, M. (2018). Pengaruh Literasi Keuangan dan Inklusi Keuangan Terhadap Kinerja Usaha Kecil di Kalimantan Timur. In Jurnal Economia (Vol. 14, Issue 1). https://journal.uny.ac.id/index.php/econo mia

Soetiono, S. (2018). Literasi Keuangan dan Inklusi Keuangan Indonesia (cetakan ke 1).Rajawali. Depok.

Susilowati, I., Putra, S., Kebumen, B., \& Kaharti, E. (n.d.). Prosiding SEMINAR NASIONAL DAN CALL FOR PAPERS Fakultas Ekonomi Universitas Tidar ANALISIS PENGARUH ORIENTASI PASAR DAN INOVASI TERHADAP KINERJA BISNIS PADA UKM DI KEBUMEN.
Tjiptono, F. , G. C. (2012). Pemasaran Strategik. . Andi Offset. Yogyakarta.

Udriyah, Tham, J., \& Ferdous Azam, S. M. (2019). The effects of market orientation and innovation on competitive advantage and business performance of textile smes. Management Science Letters, 9(9), 1419-1428.

https://doi.org/10.5267/j.msl.2019.5.009

Yanti, W. I. P. (2019). Pengaruh Inklusi Keuangan dan Literasi Keuangan Terhadap Kinerja UMKM di Kecamatan Moyo Utara. Jurnal Manajemen Dan Bisnis, 2, 1-9. 